\title{
Leading Change: Creating a Culture of Assessment
}

\author{
Patricia M. Dwyer
}

Shepherd College

In Leading Change, John Kotter (1996) outlines an eight-step process to effect major organizational change. At Shepherd College, the assessment process that evolved into a culture of assessment mirrors the steps that Kotter describes. In 1998, Shepherd College found itself in a predicament that many colleges and universities can relate to: slated for an accreditation visit in 2002 with campus assessment efforts stalled at every turn. A new director organized an assessment task force, established a template for assessment plans and reports, and began grassroots education about assessment. Over the four years, a vision that aligned assessment with improving student learning effected dramatic changes in attitudes about assessment.

\section{INTRODUCTION}

hepherd College is part of the public school system of West Virginia. Lo-

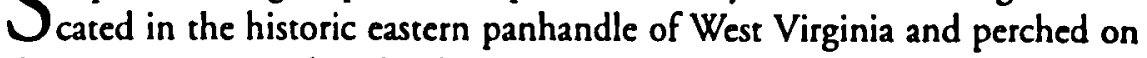
the Potomac River, the school attracts students primarily from West Virginia, Virginia, Maryland, Washington, D.C., and Pennsylvania. Approximately 4,000 students are enrolled in 197 undergraduate majors, minors, and concentrations. The college also has a community college component and is currently developing selected graduate programs.

\section{Leading Change}

How does one lead change? Is change a top-down initiative, a grassroots movement, or some combination of the two? Successful assessment programs and organizations that have experienced transformation point to a 
model of leadership that taps the resources and talents of the group. The outcome is a common sense of purpose and responsibility - a vision that can be embraced by the entire community. In The Dance of Change, Senge et al. (1999) define this kind of leadership "as the capacity of the human community to shape its future, and specifically to sustain the significant processes of change required to do so" (p. 6). The human community that Senge describes sustains a certain "creative tension, [that is,] energy generated when people articulate the vision and tell the truth (to the best of their ability) about current reality" (p.16). Creative tension is at the heart of the scenario that Loacker and Mentkowski (1993) explore in their essay "Creating a Culture Where Assessment Improves Student Learning." They describe Alverno College President Sister Joel Read's call for the faculty to engage in a process of critical inquiry to inform curricular change. The key to success in moving through these turbulent waters was asking the critical questions-what kind of person are we as educators seeking to develop?-and involving both faculty and administrators in formulating the answers. Loacker and Mentkowski point to the sense of co-responsibility that contributed to the college's transformation.

\section{Kotter's Theories on Effecting Change}

At the 2002 Professional and Organizational Development Network in Higher Education conference in Atlanta, I was fortunate to participate in Dr. Ann Lucas's workshop on nurturing leadership skills in department chairs. In her presentation, Dr. Lucas presented John Kotter's theoretical model for understanding ways that change takes hold and becomes effective in an organization. As I listened to her exploration of Kotter's eight-step process, I was struck with how similar the process was to the incorporation of our assessment program at Shepherd College. At the outset of this chapter, let me thank Ann for introducing me to Kotter's theory.

Kotter's eight-stage process of creating major change is outlined in his book Leading Change (1996). These are:

\section{Step 1. Establishing a Sense of Urgency}

- Examining the market and competitive realities

- Identifying and discussing crises, potential crises, or major opportunities 


\section{Step 2: Creating a Guiding Coalition}

- Purting together a small group with enough power to lead the change

- Getting the group to work together like a team

\section{Step 3: Developing a Vision and a Strategy}

- Creating a vision to help direct the change effort

- Developing strategies for achieving that vision

\section{Step 4: Communicating the Change Vision}

- Using every vehicle possible to constantly communicate the change vision

- Having the guiding coalition role model the behavior expected of employees

\section{Step 5: Empowering Broad-Based Action}

- Getting rid of obstacles

- Changing systems or structures that undermine the change vision

- Encouraging risk taking and nontraditional ideas, activities, and actions

\section{Step 6: Generating Short-Term Wins}

- Planning for visible improvements in performance, or "wins"

- Creating those wins

- Visibly recognizing and rewarding those people who made the wins possible

\section{Step 7: Consolidating Gains and Producing More Change}

- Using increased credibility to change all systems, structures, and policies that don't fit together and don't fit the vision

- Hiring, promoting, and developing people who can implement the change vision

- Reinvigorating the process with new projects, themes, and change agents 


\section{Step 8: Anchoring New Approaches in the Culture}

- Creating better performance through customer- and productivity-oriented behavior

- Articulating the connections between new behaviors and organizational success

- Developing a means to ensure leadership development and succession

The eight-step process that Kotter identifies interfaces with the assessment process implemented on Shepherd's campus and helps to explain why the assessment process succeeded, that is, that a true culture of assessment developed over time, and more importantly, has been sustained beyond the accreditation visit that created the initial urgency. The following section describes the connections between Kotter's steps and the successful process for implementing assessment at Shepherd College.

\section{Making the Connections}

\section{Step 1. Establishing a Sense of Urgency}

- Examining the market and comperitive realities

- Identifying and discussing crises, potential crises, or major opportunities

Facing an accreditation visit was all the urgency we at Shepherd College needed. But the major opportunities cited in this stage can provide a more positive spin to the urgency that gets a campus to move forward with an assessment process. Some opportunities may include a call to major curricular reform as in the case of Alverno College, a realignment of schools or programs, outside funding for a particular project that demands assessment, and so forth. Urgency does nor have to be equated with panic. Integral to a good assessment program is collection of data and reflection on the learning goals of a program. Often faculty and administrators need a jump-start to make these activities a priority.

\section{Step 2: Creating a Guiding Coalition}

- Purting together a small group with enough power to lead the change

- Getting the group to work together like a team 
Shepherd College had formed a plethora of assessment committees, but very little action had been taken. When putting together a guiding coalition, the director invited selected faculty and staff members who would work well together and would be good ambassadors for the assessment program. In addition, the name change to Assessment Task Force contributed to the different tone that the group hoped to communicate. Unlike other committees that tend to be top-heavy with administrators, the task force had one dean who represented the other administrators. Staff, faculty, and, most importantly, students were invited to participate. The task force met once a month and planned assessment workshops, helped departments construct assessment plans and reports, and generally offered assistance where needed.

\section{Step 3: Developing a Vision and a Strategy}

- Creating a vision to help direct the change effort

- Developing strategies for achieving that vision

This step was perhaps the most important in the assessment process. Our vision took the form of connecting assessment to improving student learning. That was the mantra whenever the director was discussing assessment issues with chairs or faculty, staff or students. The assessment office became Assessment of Student Learning-the secretary answered the phone with that phrase, the office stationery communicated that message, every newsletter and announcement always linked assessment and student learning. At this same time, the director proposed that a statement be added to the institutional mission that would highlight the importance of improving student learning. The following was added to the college mission statement in 2000: "Student learning is central to the culture of our institution, finding ways to improve student learning is a continuous process."

Strategies for achieving the vision included yearly assessment plans and reports from each department and unit. While this cycle demanded a quick turnaround to complete the assessment loop, it also provided more immediate feedback (and deadlines) for departments who were starting assessment activities for the first time. In addition, departments identified three-and only three-learning goals to be assessed each year. This kept the process from sceming overwhelming, especially for beginners.

To support assessment efforts, the director invited departments to go off campus for an assessment retreat. The Office for Assessment of Student Learning made arrangements and paid for meals, and the director offered to facilitate 
a discussion with the department about program learning goals. Throughout the academic year, the director organized grassroots faculty development opportunities to continue educating the campus about assessment.

\section{Step 4: Communicating the Change Vision}

- Using every vehicle possible to constantly communicate the change vision

- Having the guiding coalition role model the behavior expected of employees

In communicating the vision, the Office for Assessment of Student Learning created a newsletter, Assessment of Student Learning at Shepherd, that showcased assessment's link to student learning; initiated a speaker series, Focus on Student Learning, with faculty and staff as guest speakers presenting topics of interest; and organized a brown-bag lunch discussion group, Food for Thought, on issues of teaching and learning.

The guiding coalition, our Assessment Task Force, served as support for the campus, and in communicating with departments or individuals, it always linked assessment with student learning. The task force members reviewed yearly plans and gave feedback and advice about the format of the plan. Thus, they made sure that each plan was linked to the mission, had three learning outcomes to be assessed, had two means of assessing each ourcome (both direct and indirect), and had a benchmark to determine success. Task force members would not comment on the actual outcomes being assessed but only gave feedback on the components of a good plan.

\section{Step 5: Empowering Broad-Based Action}

- Getting rid of obstacles

- Changing systems or structures that undermine the change vision

- Encouraging risk taking and nontraditional ideas, activities, and actions

Getting rid of obstacles? Perhaps a more accurate description on our campus was working around the obstacles. For example, the director called her team a task force rather than a committee. This kept the group from stepping on the toes of already established assessment committees who were not moving the process forward. In addition, the task force was housed under strategic planning rather than the faculty senate, known for its propensity to stall or obfuscate important issues. 
Early on in the assessment process, the task force wanted to encourage departments to assess those outcomes that would be more risky; in other words, departments should not assess only those outcomes that felt safe or ones that were guaranteed to produce good numbers. Thus, the task force created a campus philosophy of assessment in which it asserted that assessment results would not be used for punitive purposes.

Initially, each department was automatically awarded $\$ 500$ to defray the cost of assessment materials. At the end of the first year under the new director, very little of the money had been utilized; other than ordering tests, most departments did not know how to use the money. In the second year, the director shifted to mini-grant applications and encouraged departments to apply for projects. After the first year of awards, projects were advertised to the general campus population as a way to generate more ideas for using assessment funds.

\section{Step 6: Generating Short-Term Wins}

- Planning for visible improvements in performance, or "wins"

- Creating those wins

- Visibly recognizing and rewarding those people who made the wins possible

Our "wins" in the first year were simply getting assessment plans and reports completed for each department/program. While they weren't perfect, the completion of the assessment loop gave departments some data to work with-and department members discovered that they could learn something about their programs that could be very valuable. As assessment cycles afforded more information to the departments, they were encouraged to use results in seeking budget increases.

We visibly recognized these wins by showcasing departments' assessment efforts in the newsletter or through the speaker series. In addition, we started a student achievement day; here students submitted proposals to present projects or papers to the school community.

\section{Step 7: Consolidating Gains and Producing More Change}

- Using increased credibility to change all systems, structures, and policies that don't fit together and don't fit the vision 
- Hiring, promoting, and developing people who can implement the change vision

- Reinvigorating the process with new projects, themes, and change agents

Increased credibility for our assessment process came with the commendation we received on our assessment efforts from our North Central accreditation team. In 2002, the college also restructured and created the position of dean of teaching, learning, and instructional resources to expand on assessment activities and to develop a center for teaching and learning. New activities included student and faculty learning communities and a reinvigorated writing-across-the-curriculum program.

\section{Step 8: Anchoring New Approaches in the Culture}

- Creating better performance through customer- and productivity-oriented behavior

- Articulating the connections between new behaviors and organizational success

- Developing a means to ensure leadership development and succession

Our better performance included changes in the curriculum, prompred by assessment, to better meet student needs. Organizational success in our accreditation visit contributed to making assessment more a part of the fabric of the institution. New leadership has emerged through the faculty learning communities, the in-house speaker series, the interdisciplinary student learning communities that bring faculty together in teaching initiatives, and a summer teaching institute for faculty to revise a course based on active learning strategies.

\section{Conclusion}

Kotter's eight-step process of change provides a dynamic framework for adopting new programs like the assessment process at Shepherd College. Forming a guiding coalition and a vision provides the foundation and the inspiration for action; aligning resources to that vision and creating wins ensures that the change will last. Two years beyond our accreditation, departments and academic support units continue to explore ways to revise curriculum or change teaching strategies to improve student learning. While we were not aware of Kotter's theory at the outset of our process, we are gratified to know why it was successful. 


\section{References}

Kotter, J. P. (1996). Leading change. Boston, MA: Harvard Business School Press.

Loacker, G., \& Mentkowski, M. (1993). Creating a culture where assessment improves learning. In T. W. Banta (Ed.), Making a difference: Outcomes of a decade of assessment in higher education (pp. 5-24). San Francisco, CA: Jossey-Bass.

Senge, P., Kleiner, A., Roberts, C., Ross, R., Roth, G., \& Smith, B. (1999). The dance of change: The challenges to sustaining momentum in learning organizations. New York, NY: Currency Doubleday. 